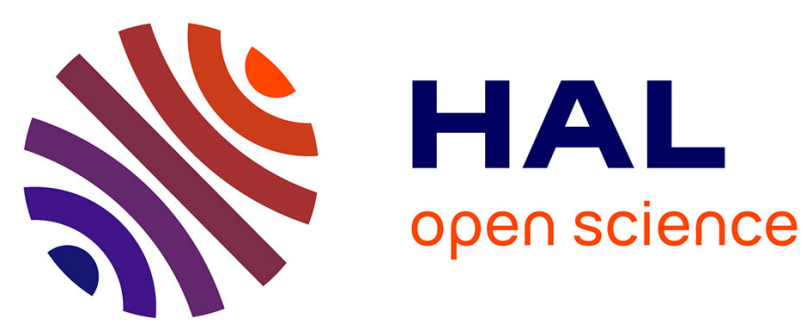

\title{
PHYSICS-BASED SCENARIO OF THE 2007 CHUETSU-OKI EARTHQUAKE
}

F Gatti, Fernando Lopez-Caballero, Lúcio de Abreu Corrêa, D Clouteau, R Paolucci

\section{- To cite this version:}

F Gatti, Fernando Lopez-Caballero, Lúcio de Abreu Corrêa, D Clouteau, R Paolucci. PHYSICSBASED SCENARIO OF THE 2007 CHUETSU-OKI EARTHQUAKE. 6th ECCOMAS Thematic Conference on Computational Methods in Structural Dynamics and Earthquake Engineering, Jun 2017, Rhodes, Greece. pp.C17465. hal-01546804

\section{HAL Id: hal-01546804 https://hal.science/hal-01546804}

Submitted on 26 Jun 2017

HAL is a multi-disciplinary open access archive for the deposit and dissemination of scientific research documents, whether they are published or not. The documents may come from teaching and research institutions in France or abroad, or from public or private research centers.
L'archive ouverte pluridisciplinaire HAL, est destinée au dépôt et à la diffusion de documents scientifiques de niveau recherche, publiés ou non, émanant des établissements d'enseignement et de recherche français ou étrangers, des laboratoires publics ou privés. 


\title{
PHYSICS-BASED SCENARIO OF THE 2007 CHUETSU-OKI EARTHQUAKE
}

\section{Filippo Gatti $^{1,2}$, Fernando Lopez-Caballero ${ }^{1}$, Lúcio de Abreu Corrêa ${ }^{1}$, Didier Clouteau ${ }^{1}$ and Roberto Paolucci ${ }^{2}$}

\author{
${ }^{1}$ Laboratoire MSSMat - CentraleSupélec - Université Paris Saclay \\ Grande Voie des Vignes, 92290 Châtenay-Malabry \\ e-mail: \\ \{filippo.gatti,fernando.lopez-caballero,lucio.de-abreu-corre,didier.clouteau\}@ centralesupelec.fr \\ 2 DICA - Politecnico di Milano \\ P.zza Leonardo da Vinci 32, 20133 Milano \\ e-mail: \{filippo.gatti,roberto.paolucci\}@polimi.it
}

Keywords: Physics-based simulation, earthquake strong ground motions, Spectral Elements Methods

\begin{abstract}
This study presents a preliminary calibration of a large-scale seismological model of the $M_{W} 6.6$ Niigata-Ken Chuetsu-Oki (Japan) earthquake of July, $16^{\text {th }}$ 2007. The strong ground motion affected a wide area in the surrounding of the Kashiwazaki-Kariwa Nuclear Power Plant $(K K N P P)$. Due to the relative small source-to-site distance and shallow hypocenter depth, this seismic scenario resulted very interesting and well documented (a consistent database of seismic recordings is available). In this context, the test-case represents a suitable benchmark for the work-packages of the SINAPS@ project.SINAPS@ is the first French research project with the objective to quantify the uncertainty of the procedures to estimate the seismic risk. In this context, an omni-comprehensive approach is followed, modelling the wave-propagation from the fault to the structural components. This study is intended to describe the steps to build up and calibrate a reliable seismic scenario, capable to provide a synthetic wave-field at the regional scale. This objective is pursued by (1) assessing a stratified geological model for the Niigata region, (2) testing the effect of the source parameters in a kinematic approach (e.g. the rise time and the shape of the Source Time Function) and (3) checking the topography effect. A series of 3D source-to-site numerical simulations of the $M_{W} 4.4$ NCOEQ2007 aftershock was therefore carried out with this regard (performed by means of the Spectral Element Method, SEM). The seismic scenario was calibrated with the aid of the semi-analytical solution provided by the Wave-Number Integration Method (WNI) and by comparing the synthetics with the recordings at several locations (i.e. the KNET-Kik-Net stations nearby and the KKNPP site). Finally, the forward physics-based analysis ended up by providing broad-band synthetic time-histories to be exploited in further studies as a reliable regional incident wave-field for the engineering bedrock
\end{abstract}




\section{INTRODUCTION}

The $2007 \mathrm{M}_{W} 6.6$ Niigata-Ken Chüetsu-Oki earthquake (NCOEQ2007) struck a $100 \mathrm{~km}$ wide area along the Japanese mid-west coastal area (Figure 11). The strong ground motion occurred as a result of a buried reverse-slip motion, nucleated at an the estimated hypocentral depth of $8 \mathrm{~km}$. No significant surface rupture was detected [1].

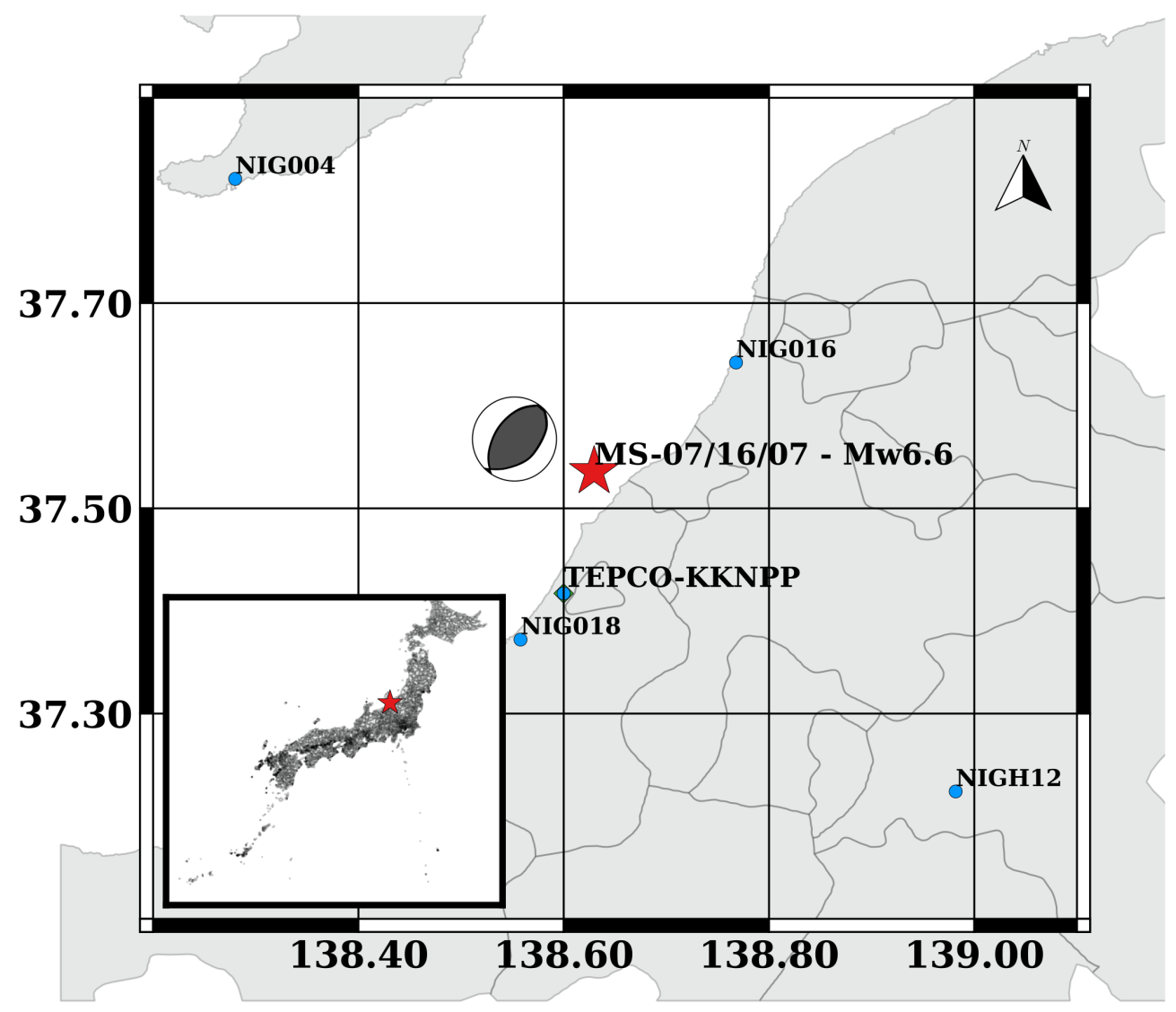

Figure 1: Map of the Niigata region, surrounding the Kashiwazaki-Kariwa Nuclear Power Plant . Some stations of the Japanese strong ground motion seismograph networks K-NET and KiKNet are shown (blue circles), along with the TEPCO-KKNPP site (green diamond) and the NCOEQ2007 epicenter (red star).

The affected area is located in the southern Niigata prefecture, in the adjacent surroundings of the Kashiwazaki-Kariwa Nuclear Power Plant (KKNPP), i.e. at a Joyner-Boore distance $\mathrm{R}_{J B}=0$ $\mathrm{km}$, corresponding to a rupture distance $\mathrm{R}_{r u p}=16 \mathrm{~km}[2]$ ). Peak horizontal ground accelerations of $0.68 \mathrm{~g}$ were measured in Kashiwazaki City, as well as at the reactor floor level of the KKNPP (the world's largest nuclear reactor). The nuclear site underwent nearly twice the Peak Ground Acceleration considered for the plant design [3]. Critical structures appeared to have performed well given the intensity of the ground shaking and the large ground settlements (mainly due to redundant overdesigned structures) [4]. A few harmless breakages, failures and fire took place at the plant along with a leak of radioactive gases and some small amount of water leakage from the spent fuel pool. The reactor units were safely powered down as soon as the acceleration values exceeded the design limit. According to the preliminary post-seismic reconnaissance [5], evidence of liquefaction near the waterfront was found and a landslide damaged the KKNPP. 
The NCOEQ2007 represents a very interesting yet complex earthquake case study, mainly for two reasons: (1) despite the dense recording network in the surrounding (e.g. the Japanese strong ground motion seismograph networks K-NET and KiK-Net, as well as the seismometer network installed at the KKNPP), the faulting mechanism is still partially unresolved [6, 7]; (2) the observed spatial variation ground motion is likely to be due to a geological folding structure near the KKNPP [8, 9, 10]. The NCOEQ2007 main shock (MS) occurred in the upper crust with a steeply dipping reverse fault mechanism under the north-west/south-east compression, which is quite usual in the northern part of the so called Niigata-Kobe Tectonic Zone (NKTZ), placed in the central coastal area of the Japan Sea. Two conjugate fault planes were estimated, dipping north-westward (NW) and south-eastward (SE) respectively. The overall wave-form analyses confirm that both the fault planes are possible [11, 12, 13, 14]. However, from the aftershock distribution determined by the NIED Hi-net routine analysis, the SE dipping alignment is roughly estimated and most of the authors finally endorsed the assumption of SE dipping plane as the causative of NCO earthquake [15, 13, 14].

The observed wave-forms recorded at KKNPP site show three distinct pulses at many sites (although the second pulse was not always clearly identified) [9]. From this recorded evidence, several authors inferred three major asperities on the causative fault plane [14, 16, 13] that radiate more energy than their surroundings. However,it was also pointed out that the peak ground velocity on the south side of the KKNPP is much larger than that on the north side [17, 9]. Despite the open discussion, this difference is likely to come from the folding structure below the KKNPP [9]. Due to the inherent complexities, a few detailed ground motion scenarios of the NCOEQ2007 are available. Ducellier and Aochi [18] and Aochi et al. [1] performed a 3D forward physics-based analysis (exploiting the Finite Difference Method,FDM) by comparing the two slip patches proposed by Aoi et al. [6] and by Hikima and Koketsu [19]. The authors solved at first the epistemic uncertainty on the geological profile. In doing so, they employed the smallest recorded aftershocks, so to exclude any complex source effect. They first adjusted the crustal 1D soil profiles estimated for the Niigata region. In a second phase, they improved the coarse crustal model by refining it with a shallow structural model based on either 3D tomography, or on various $1 \mathrm{D} / 2 \mathrm{D}$ profiles and geological interpretation. However, due to computational limits, their study is reliable within the frequency band $0.1-0.9 \mathrm{~Hz}$ (improved to $1.0 \mathrm{~Hz}$ in [20]), on a regional model $110 \mathrm{~km} \times 120 \mathrm{~km} \times 30 \mathrm{~km}$. Tsuda et al. [9] instead, tested the slip patch proposed by Shiba et al. [16] focusing on the effect of the folding structure beneath the KKNPP and to its effects on the observed ground motion incoherence. Their analyses (performed via FDM) reached up to $4 \mathrm{~Hz}$. They could reproduce the general features of ground motion on the KKNPP events which occurred on the fault area of main shock (Chuetsu-Oki earthquake) and the aftershock of the 2004 Chuetsu earthquake.

Following the earlier studies on the NCOEQ2007, a new (yet preliminary) 3D physics-based earthquake scenario is herein presented. In particular, this paper focuses onto the methodological approach adopted to construct and calibrate it. The uncertainty quantification mainly targeted the choice of the crustal geology and the topography effect (the presence of the Japan sea was however disregarded). The plan of the performed numerical exercise can be unravelled into the following points:

- testing the influence of different geology profiles onto final wave-forms at some location in the surrounding of the NCOEQ2007 epicentre. Several 1D geological profiles have been tested, either as discontinuous layered geology, or by smoothing it up with a piece- 
wise linear approximation;

- performing a sensitivity analysis upon the seismic source time functions (STF), featuring the kinematic description of a point-wise double couple seismic source;

- testing the effect of the topography on the synthetic wave-forms;

- propose a broad-band (depending on the source radiated frequency content) synthetic incident wave-field at the engineering bedrock issued from 3D forward physics-based numerical simulation

Two numerical tools were employed in this work: (1) the 1D semi-analytical solution provided by the Wave-Number Integration method (WNI) (proposed and numerically implemented by Hisada [21, 22] ) and (2) the 3D Spectral Element Code software (SEM3D) [23, 24], developed within the framework of the SINAPS@ project (as a collaboration between CentraleSupélec, the Commissariat l'énergie atomique et aux énergies alternatives (CEA) and Institut de Physique $d u$ Globe de Paris). The former is alternatively employed to find a most adequate geological profile (by running a simulation over a $\mathrm{M}_{j} 4.4$ aftershock, denoted by AS from now on) and the most adequate slip distribution (by running a simulation of the NCOEQ2007 main shock (MS) featured by the previously chosen geological model). The fairly good comparison between WNI method and the results and recordings is valid between $0.05-0.5 \mathrm{~Hz}$. At this point, SEM3D was adopted to simulate the $3 \mathrm{D}$ wave propagation over a broader frequency range (up to $\approx 5 \mathrm{~Hz}$ ). In particular, SEM3D was used for manifold purposes, i.e. to test different STFs for a pointwise double couple approximation of the AS earthquake, to test the topography effect on the synthetic wave-forms.

\subsection{Tools and methodology to build-up an earthquake physics-based scenario}

Traditionally, the strong ground motion characterization is addressed and described by means of its peak values (e.g. the Peak Ground Acceleration) and wave-forms and of other indicators (e.g. the Arias intensity). In this context, any of this features may be expressed as the convolution of several factors, namely: (1) the source effect E, (2) the path effect P, (3) the site effect $\mathrm{G}$ and (4) the instrument/type of motion I [25]. Following this logic, the seismological model is herein built-up by tuning each feature stand-alone so to progressively enrich the original skeleton model. At any step, a back-verification check is done, so not to spoil the model by progressively dropping simplified assumptions, but to refine it instead.

Another crucial distinction made herein to ease the understanding and modelling of a large broad-band seismic scenario concerns the origin of the synthetic frequency content. Most of the slip distribution estimations available in the literature are derived from longer period ground motions (strong-motion time-histories, teleseismic velocity seismograms, GPS and InSar measurements) and therefore valid within a frequency range $\approx 0.05-0.5 / 1 \mathrm{~Hz}$. At these longer periods, ground motions are predominantly deterministic and their wave-forms can be accurately modelled using simple descriptions of the source and crustal structure. The mentioned WNI method is naturally appropriate to this end, since it couples the need of a relative small amount of parameters with a reduced computational cost to simulate the complete 3D wave propagation field radiated from an extended kinematic seismic source in a layered half-space. Typically, WNI method deterministic analyses are reliable in a $0.05-3 \mathrm{~Hz}$ frequency band. However, several authors (e.g. [26, 27, 28]) agreed on the fact that despite their modest accuracy, long-period deterministic models are relevant for the simulation of artificial high-frequency 
signals, since the main uncertainty, both for short- and long-period wave-forms, resides into the methods to characterize the source mechanism [28]. For instance, slip models of shallow crustal earthquakes (as the NCOEQ2007) are characterized by strong spatial variation in slip on the fault surface, including the asperities [28]. However, while travelling towards the surface, the wave-field gets enriched at high-frequencies (i.e. $2-15 \mathrm{~Hz}$ ) when encountering finer deposits in the shallow part of the Earth's crust and topographical surface [28]. This spectral component is predominantly stochastic and it is extremely interesting for structural analysis. Therefore, the numerical model of the NCOEQ2007 scenario was designed to propagate seismic energy up to $5 \mathrm{~Hz}$. The SEM (i.e. an high-order version of the Finite-Element Method) was employed due to its higher accuracy in solving wave-propagation problems and due its easy and scalable extension to parallel implementation [29]. The SEM has been successfully used (e.g. $[30,31,32]$ ) to simulate 3D seismic wave propagation in complex geological media (and topographical surface) at regional scale with increasing resolution. However, despite the efficiency of the numerical tool used in this study, the calibration of huge 3D large-scale seismic scenarios was conducted with the aid of a less cumbersome yet simplified semi-analytical/numerical tool (i.e. WNI method). In this way, the initial gross epistemic uncertainty is rapidly trimmed and more refined numerical tools (i.e. SEM3D) are then employed to refine the earthquake scenario.

\section{PRELIMINARY CHOICE OF A SUITABLE 1D GEOLOGICAL PROFILE}

With respect to the Niigata-Ken Chüetsu-Oki earthquake, several different stratified geologies (varying station by station) have been calibrated from the aftershocks recordings [33, 12, 15. 13]. Those 1D profiles are generally obtained by wave-form inversion procedures, performed on narrow time windows ( $\approx$ rupture duration) centered on the main phase of S-wave and reaching a maximum frequency of $1 \mathrm{~Hz}$. Therefore, in an early stage of the seismic scenario calibration, they are employed to provide a reasonable synthetic wave-field at the regional engineering bedrock, supposed underlying the shallow folded sedimentary strata. At this point, it is important to remark that the resolution of those geological profiles is approximately $0.5 \mathrm{~km}$. The large scale model may be equipped with complex 3D geological model (e.g. [7, 34, 35]) in a second instance [9, 18, 1, 33, 36, 19, 12]. In this task, some of the mentioned approximated geological profiles were tested. The latter refers to the Niigata region around KKNPP and they are portrayed in Figure 2. The shallow folded structure is made of thick sedimentary layers in the surrounding of the KKNPP site, which is bounded by the south-east mountains (mainly composed by hard rock). The complex lateral variations in basement structure along the NW-SE The epistemic uncertainty on the geological profile was solved by running a parametric analysis WNI method. The $\mathrm{M}_{j} 4.4$ aftershock of July 16, 21.08h, was considered, which nucleated near-by one of the three major fault asperities at a depth of $11 \mathrm{~km}$ [9] by detecting the polarity for the P-wave first motion (performed by the Hi-net [37]) and by considering the Centroid Moment Tensor analysis provided by F-net data [38]. The Kik-Net and KNET recording stations were employed at this point, along with the recorded time-histories at the KKNPP (device KSH-SG4, placed at G.L.-250m at the Service Hall of the nuclear site). The parametric analysis lead to the choice of the soil profile referenced as to Aochi2013 in Figure 2 and proposed by Aochi et al. [15] (although a satisfactory match has been obtained for other soil profiles). Figure 3 show a fairly good comparison obtained at several stations in the surroundings of the Kashiwazaki-Kariwa Nuclear Power Plant . A Brune's source model was adopted (see the discussion in Section 3.3 , with frequency corner $f_{C}=1 \mathrm{~Hz}$, coherently with the measured magnitude [39]. One single unitary sub-fault was considered herein to simulate the small $\mathrm{M}_{j}$ aftershock. In accordance with Aochi et al. [15], the recordings and the synthetics 


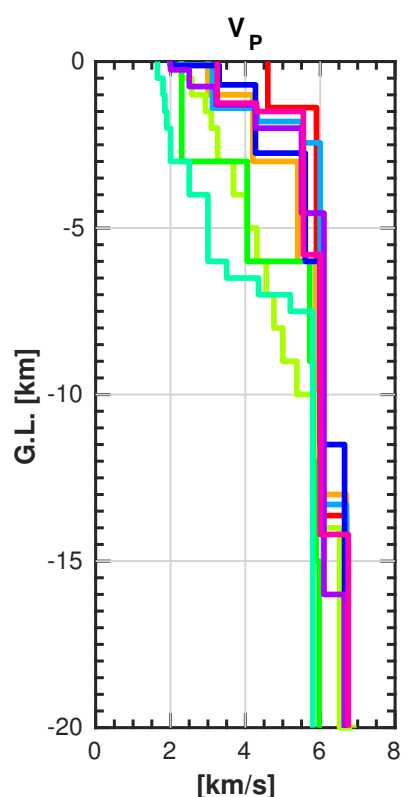

(a)

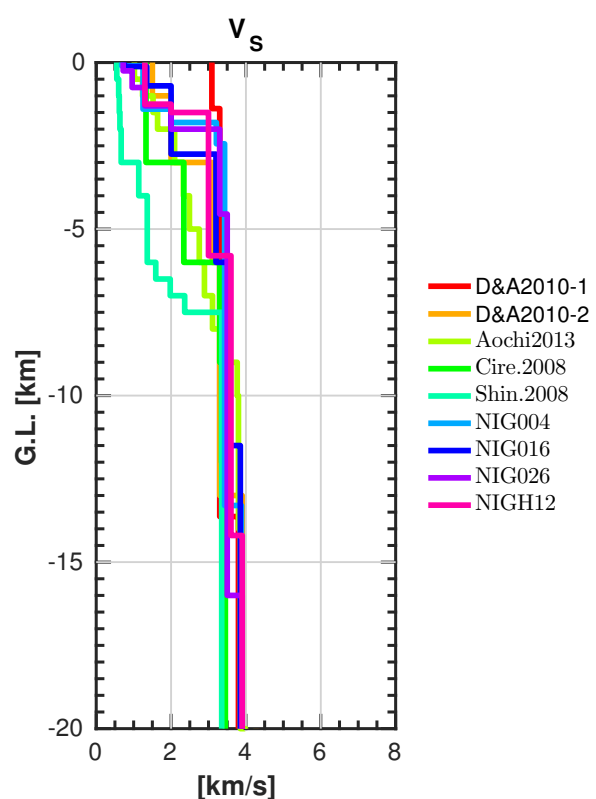

(b)

Figure 2: Comparison of $\mathrm{P}$ and S-wave velocity of the Niigata area, (a) $V_{P}$ (b) $V_{S}$.

were band-pass filtered between $0.1-0.5 \mathrm{~Hz}$ and aligned at the time-step corresponding to the $1 \%$ of the respective Arias intensity. Aochi et al. [15] introduced a sequence of softer layers (Figure 2) at shallow depths, with the respect to the crustal models estimated the the KNET/KikNet stations (NIG004, NIG016, NIG026, NIGH12). Similar results were however obtained for the crustal models tagged as Cire.2008 and Shin.2008. Despite the local alignment, some phase shift among the simulations and the recordings is still visible for NIG004 and NIGH12, whereas in the near field (cf., NIG018, NIG016) the fit is quite good (probably due to the simple propagation path [15]). Finally, from Figure 3, it appears that the simulations performed at KKNPP site are satisfactory only along the NS direction, whereas synthetics are de-amplified along the EW direction. This might be a effect of the shallow local geology of the Niigata basin.

\section{TEST 1D GEOLOGICAL PROFILE IN 3D LARGE SCALE SIMULATIONS}

\subsection{Flat layered half-space spectral model}

The chosen 1D geological model (depicted in Figure 4b) was implemented in 3D large scale SEM numerical model (see the sketch in Figure 4a). No topography was introduced at first, so to compare the synthetics with WNI results. 10 Gauss-Lobatto-Legendre (GLL) integration nodes were chosen to grant the minimum wave-length $(\approx 200 \mathrm{~m})$ a satisfactory discretization (i.e. to reach a frequency upper bound of $\approx 5 \mathrm{~Hz}[32]$ ). The total number of degrees of freedom of the considered mesh is therefore $\approx 1.9 \cdot 10^{8}$.

\subsection{Back-verification of the model upgrade $(\mathrm{WNI} \rightarrow$ SEM3D)}

The SEM3D software was used to solve the wave propagation problem so to verify it with the WNI semi-analytical model tuned in the earlier stages of the parametric analysis (and described in Section 2).

In the Spectral Element Method formulation, material properties are assigned to each GLL 


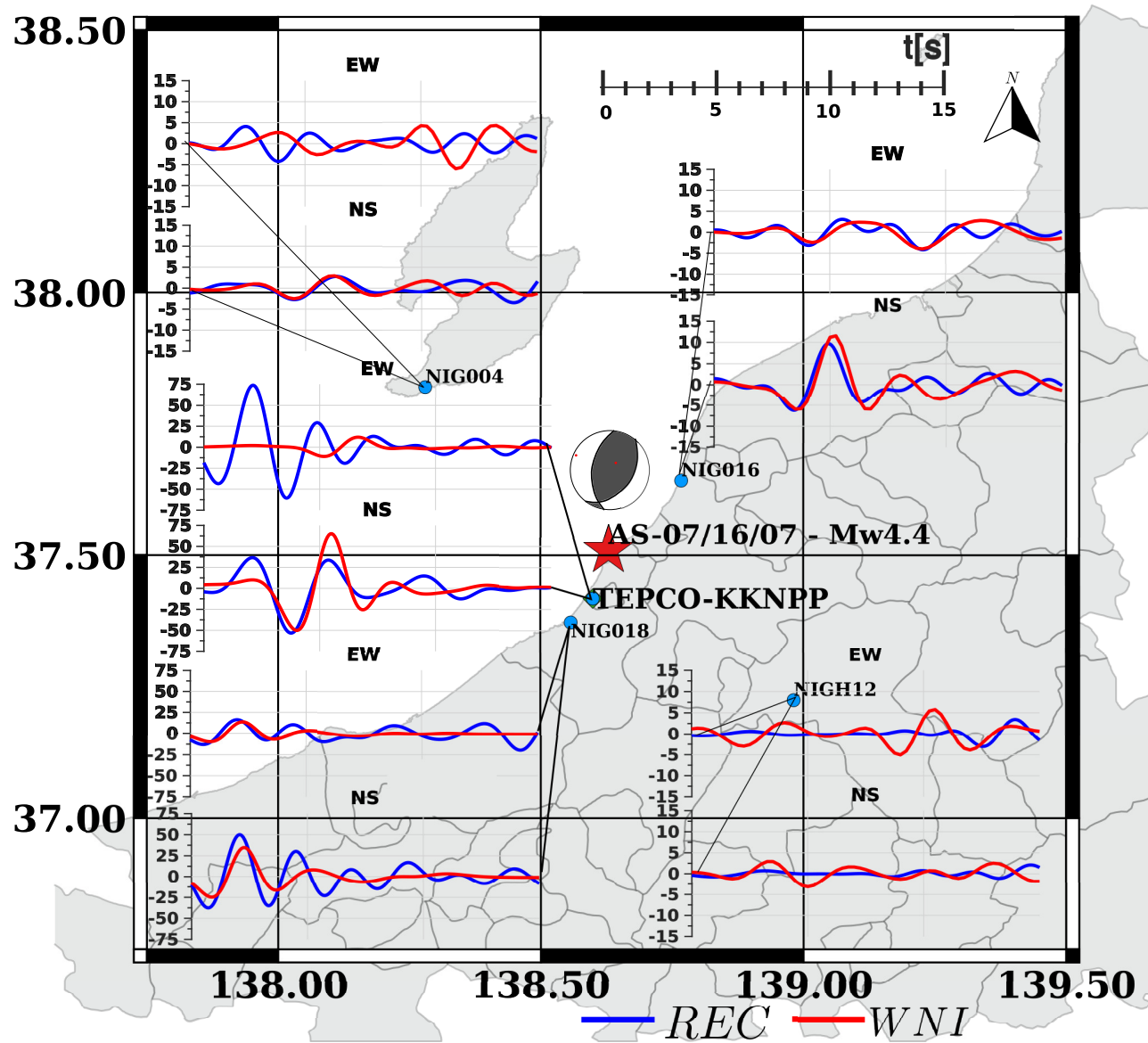

(a)

Figure 3: Simulations performed by WNI method of the NCOEQ2007 $\mathrm{M}_{j} 4.4$ aftershock of July $16,21.08 \mathrm{~h}$. Blue wave-forms represent the recorded time-histories, red wave-forms the synthetics. Both records and synthetics were base-line corrected and band-passed filtered between 0.1 and $0.5 \mathrm{~Hz}$. Synthetic wave-forms were obtained by considering the soil profile Aochi2013 (Figure 2). Velocigrams (in $\mathrm{cm} / \mathrm{s}$ ) are herein magnified by a factor 1000 and aligned with the respect at the $1 \%$ of their Arias intensity.

point. Therefore, two strategies were investigated to feature the numerical model with the varying material properties, namely (1) a direct meshing approach that adapts the computational grid to the layer-to-layer interface, so to coherently reproduce the abrupt impedance contrast along it and (2) a not honouring approach that associate to the whole independently-meshed domain a space-varying heterogeneous material map (in this case, transverse isotropic in the horizontal plane). In this standard test case (i.e. a flat and bounded layered half-space) the second strategy does not seem particularly appealing since the material interfaces are planar and horizontal and a structured mesh was adopted. Although no computational gain is achieved by using one or the other approach at this early stage, the verification test was performed in view of implementing the not honouring approach in the non-structured mesh domain portrayed in Figure 9, extruded at depth from the local Digital Elevation Model.

The numerical back-verification of the model upgrade (WNI $\rightarrow$ SEM3D) was satisfactory. For 


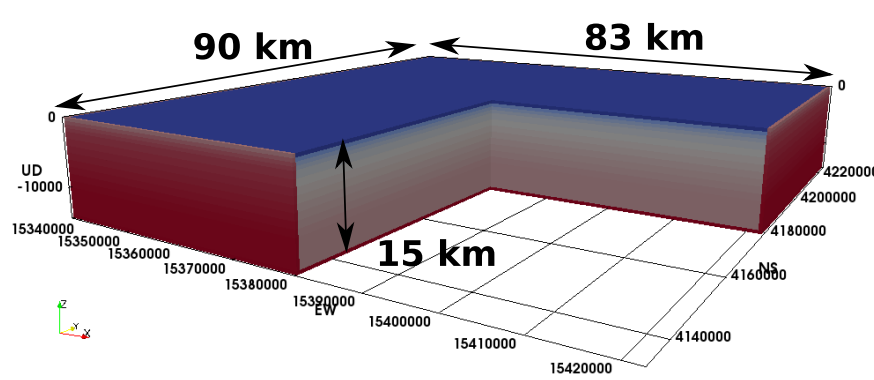

(a)

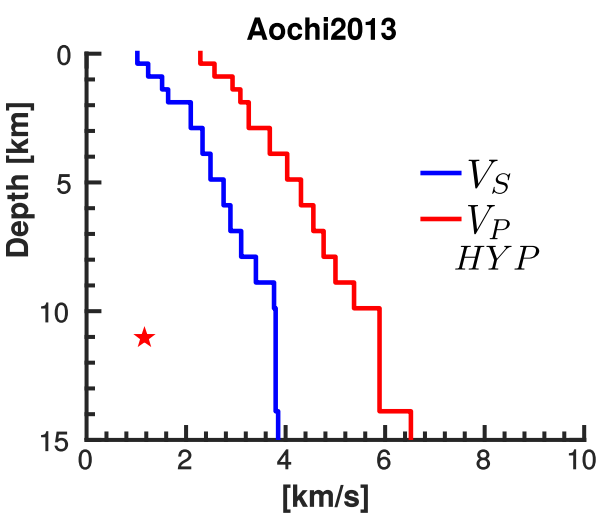

(b)

Figure 4: (a) Sketch of the SEM3D computational domain used designed to simulate a layered half space (without topography). (b) Geology model proposed by Aochi et al. [15] for the Niigata area. Blue and red profile refers to $V_{S}$ and $V_{P}$ values (in $\mathrm{km} / \mathrm{s}$ ). The red star indicate the depth of the AS hypocenter.

instance, Figure 5 shows a synoptic comparison between synthetic wave-forms filtered between 0.1 and $1.0 \mathrm{~Hz}$.

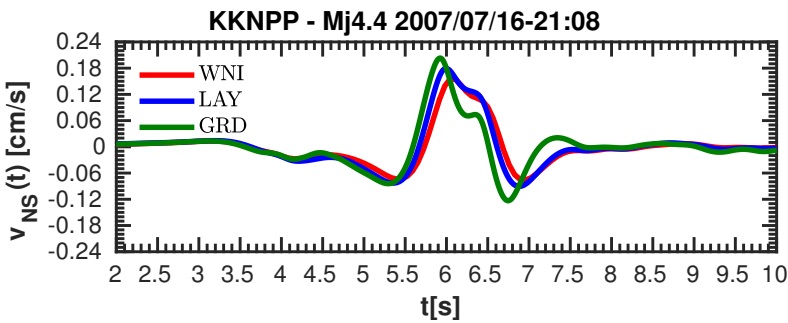

(a)

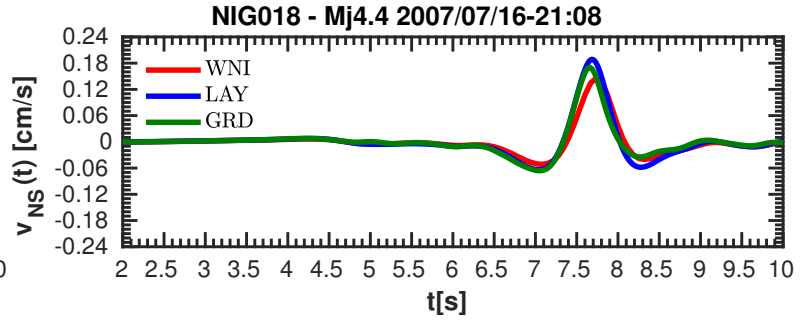

(b)

Figure 5: Numerical verification of SEM3D code, against the semi-analytical solution obtained via WNI method. Synthetic acceleration wave-forms obtained at (a) the KKNPP site (KSHSG4, G.L.-250 m, focal distance $15.1 \mathrm{~km}$ ) and at (b) the KNET station NIG018 (focal distance of $20.1 \mathrm{~km}$ ) are portrayed. A good match is achieved between the WNI method (WNI, red line) and SEM3D numerical model equipped either with a layered geology (LAY, blue line) or with a not honouring approach (GRD, green line)

\subsection{Choice of Source Time Function}

Small earthquakes (e.g. aftershocks occurring after a strong ground motion event) have been historically used to replace theoretical Green's functions [40]. This method does not require knowledge of the explicit shape of the slip time function (STF) for the small event. For instance, the WNI method exploits the empirical Green's function technique proposed by Irikura [40, 41]. The wave-form for a large event is obtained by summing the contributions of small events, correcting each slip velocity time function (SVF) according to some sort of scaling laws between a large a small event [42]. Although this approximation has been proven to be accu- 
rate enough to simulate the far-field ground motion component (see for instance [42]), one may argue that the chosen STF/SVF can influence the synthetic wave-field nearby the source. Moreover, the a priori selection of a suitable combination STF/SVF for a point-wise double-couple approximation of the seismic source is not obvious [43]. To clarify this fundamental aspect, in this section a brief parametric analysis addressing different STFs/SVFs and the respective featuring parameters is presented. SEM3D exploits a kinematic description of the seismic source [23] which consists in replacing the displacement offset on the point-discontinuity by equivalent body forces (following the approach proposed by Madariaga [44]).

Several 3D large scale analyses were performed by means of the SEM3D software. The domain geometry considered has been presented in the subsection 3.1. Two different functions describing the time evolution of the displacement offset have been examined: (1) the so called Bouchon's ramp (or smoothed ramp function[45]) $u_{S}^{T N H}(t)$, that writes:

$$
u_{S}^{T N H}(t)=\frac{A}{2}\left[1+\tanh \left(4 \frac{t-t_{S}}{\tau_{R}}\right)\right]
$$

and (2) the source model proposed by Brune [46], expressed by the following equation:

$$
u_{S}^{E X P}(t)=A\left[1-\left(1+\frac{4\left(t-t_{S}\right)}{\tau_{R}}\right) \exp \left(-\frac{4\left(t-t_{S}\right)}{\tau_{R}}\right)\right] H\left(t-t_{S}\right)
$$

The latter is well suited to approximate long-tailed Moment Rate Functions (MRF) [47]. Three are the free parameters that tune the shape and the position in time of the two mentioned STFs: the time-shift $t_{S}$, the generic rise time $\tau_{R}$ and the maximum displacement offset $A . H\left(t-t_{S}\right)$ represent the Heaviside function. The maximum slip value $A$ is spontaneously determined by relating it to the scalar seismic moment value (for the $\mathrm{M}_{j} 4.4 \mathrm{AS}$ event, the F-net indicated a seismic scalar moment $\mathrm{M}_{0}=5.21 \mathrm{e} 15 \mathrm{Nm}$ ). The time shift $t_{S}$ was manually tuned to respect the quiescent past assumption [48]. Among all, the crucial parameter results to be $\tau_{R}$. Although no explicit definition of the rise time is available neither for $u_{S}^{T N H}(t)$ nor for $u_{S}^{E X P}(t)$ [43], $\tau_{R}$ represents the duration of the slip rate pulse [43, 49]. Besides, $\tau_{R}$ is intrinsically related to the corner frequency of the SVF spectrum $f_{C}$ [52, 39], which undergoes the empirically scaling laws originally proposed by Aki [53]. This aspect is highlighted when one compares the Fourier's spectra of different SVFs. For instance, Figure 6 compares three different sources (both in time and frequency domain), tested in the AS simulations performed by exploiting the SEM3D: the red spectrum in Figure 6a refer to two Brune's slip rate time evolutions (portrayed in Figure 6b), whereas the blue and green lines correspond to the Bouchon's ramp functions. The high-frequency falloff of the two Brune's SVF follows an $\omega^{-2}$ decay, whereas Bouchon's ramps steeper decreases for $f>f_{C}$. Two different values of the free parameter $\tau_{R}$ were tested herein: $\tau_{R 1}=10^{\left(0.5\left(M_{W}-6.69\right)\right)}$ (with $M_{W}$ the moment magnitude, according to [50]) and $\tau_{R 2}=$ $2 \cdot 1.2 \cdot 10^{-8} \sqrt[3]{M_{0}}$ (with $M_{0}$ representing the scalar seismic moment, in dyne.cm, according to [51]). The two definition of $\tau_{R}$ (herein $\tau_{R 1}=0.12 \mathrm{~s}$ and $\tau_{R 2}=0.82 \mathrm{~s}$ ) are depicted in black and red lines in the captioned sub-axes in Figure 6a. The solution pertaining to the double couple point-wise simulation with the $u_{S}^{E X P}(t)$ globally has a higher frequency content, compared to the Bouchon's ramps. This result is coherently observed at different free surface receivers (such as KKNPP), although within the frequency band solved by the numerical grid (i.e. $f_{\max }=5$ $\mathrm{Hz}$ ). In that respect, the synthetic accelerograms generated by SEM3D large scale simulation of the AS event at KKNPP are traced in Figure 7. The solution obtained for AS simulation by 


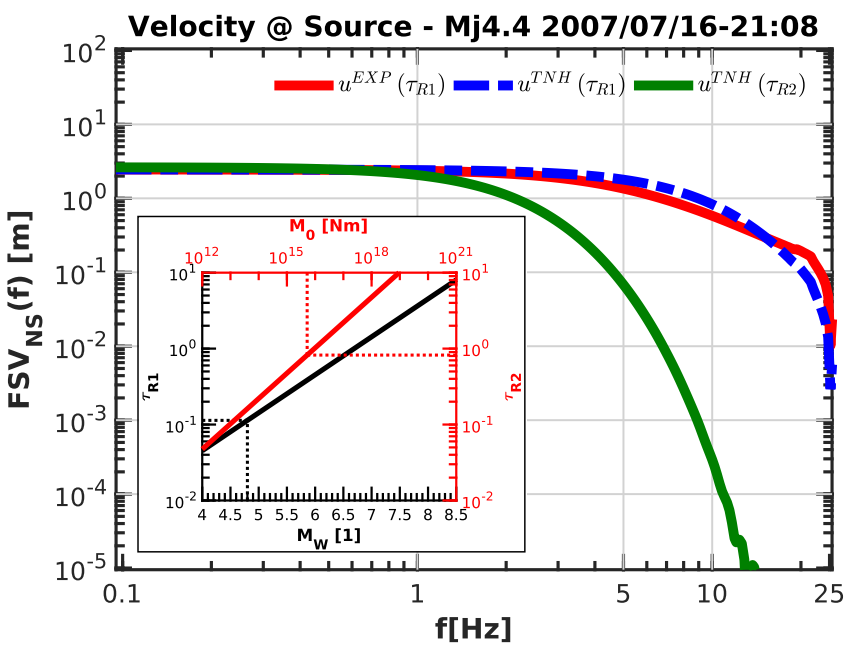

(a)

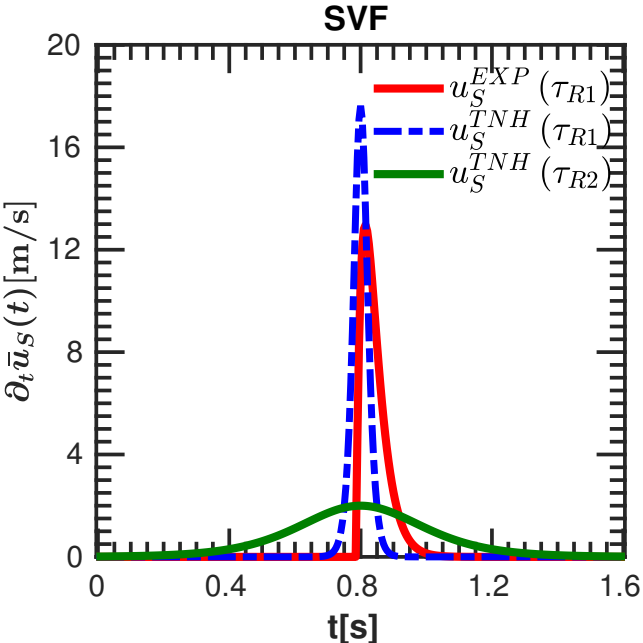

(b)

Figure 6: (a) Fourier's spectra of the tested SVFs for the AS simulation (EW component). (b) Time evolution of th source velocity functions tested for a double couple point source in SEM3D. In the captioned sub-axes in (a), two estimations of $\tau_{R}$ are depicted: as a function of the magnitude $M_{W}$ (black line, according to Dreger et al.[50]); as a function of the seismic moment $M_{0}$ (red line, according to Duputel et al.[51]).

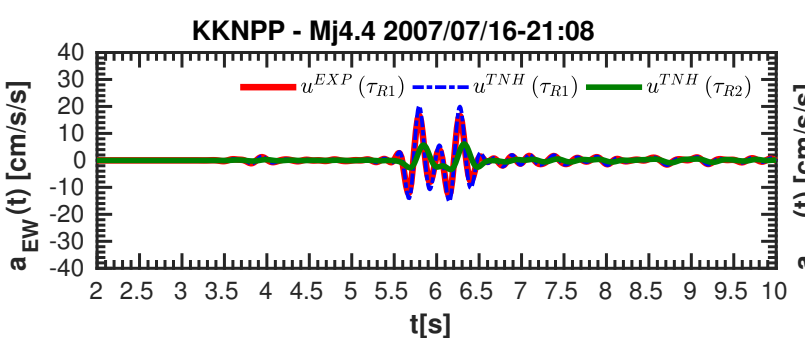

(a)

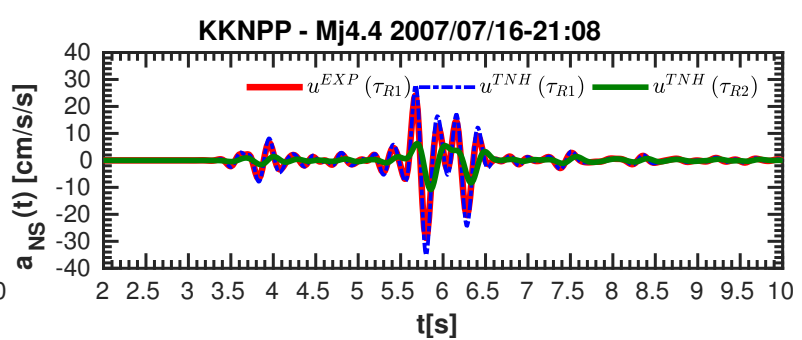

(b)

Figure 7: Numerical verification of SEM3D code: effect of the STF parameters (functional form and rise time). Synthetic wave-forms obtained at KKNPP are portrayed: (a) EW component, (b) NS component.

employing $u_{S}^{T N H}\left(\tau_{R 2}\right)$ was found to be rather poor at high-frequency and not suitable for this broad band simulation, whereas the synthetic wave-forms obtained by either $u_{S}^{E X P}\left(\tau_{R 1}\right)$ and $u_{S}^{T N H}\left(\tau_{R 1}\right)$ are comparable. However, in the following section, the synthetic peak values were compared to the ones estimated by the Ground Motion Prediction Equations, so to discriminate between $u_{S}^{E X P}\left(\tau_{R 1}\right)$ and $u_{S}^{T N H}\left(\tau_{R 1}\right)$.

\subsubsection{Comparison with Ground Motion Prediction Equations}

Ground Motion Prediction Equations (GMPEs) are traditional yet very useful tool to estimate strong ground motion parameters. Therefore, they might be employed to check if the outcomes of physics-based numerical simulation are reasonable. For instance, Fukushima et al. [54] 
proposed a rather simple GMPE, whose functional form was issued from a probabilistic seismic hazard analysis performed on PGA and PGV. K-NET and KiK-net stations in the Kanto district (Japan) were employed in the regression. The choice of this GMPE is justified by the coherency between the predicted values and AS recordings in the Niigata region. The latter are plotted in Figure 8 (in terms of geometric mean of the horizontal PGAs and PGVs) along with the prediction by Fukushima et al. [54]. The Fukushima et al. [54] GMPE predicts rather well

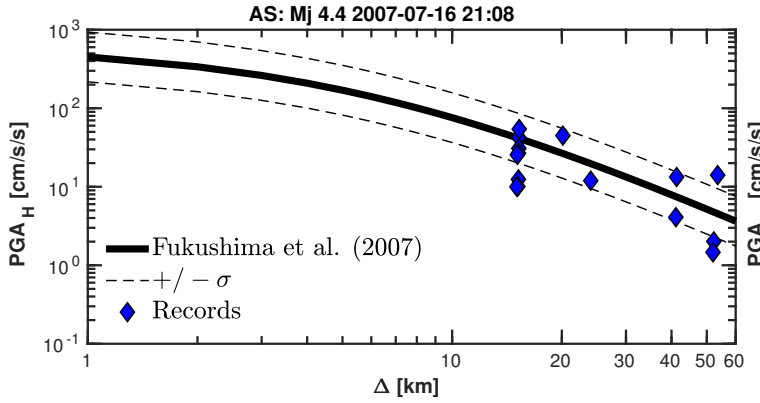

(a)

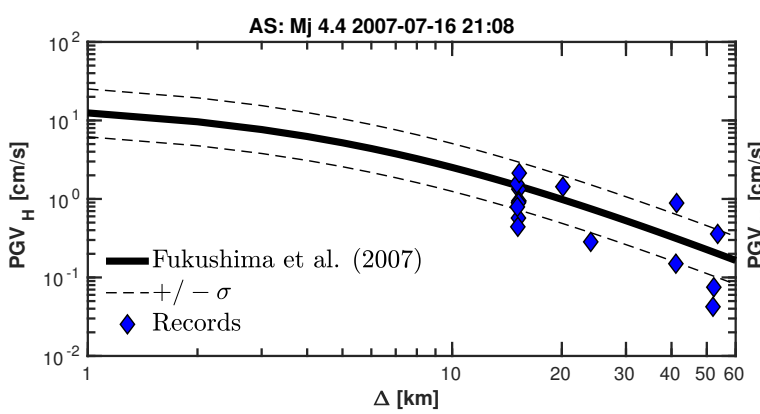

(c)

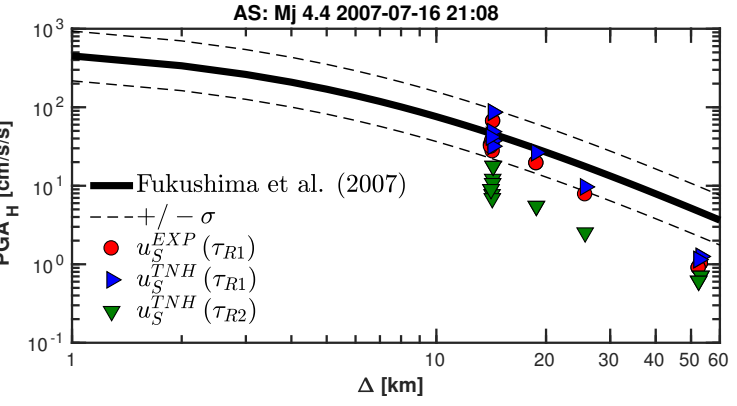

(b)

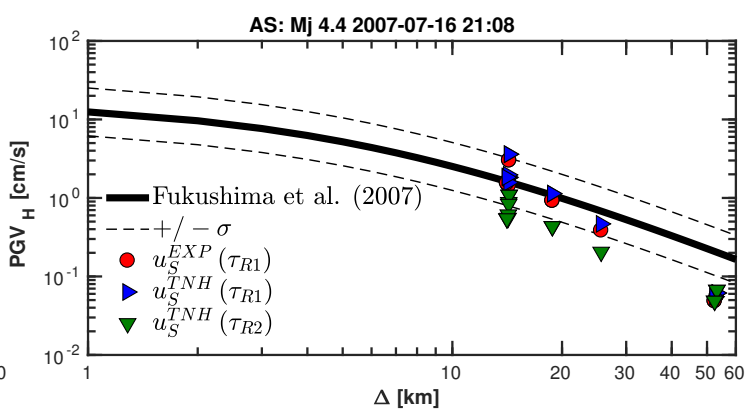

(d)

Figure 8: Horizontal geometric mean of Peak Ground Acceleration $\left(\mathrm{PGA}_{H}\right.$, portrayed in the left column) and Velocity $\left(\mathrm{PGV}_{H}\right.$, portrayed in the right column) obtained by SEM3D simulations of the $\mathrm{M}_{j} 4.4$ AS event. Synthetic peak ground motion values are compared to the GMPE proposed by Fukushima et al. [54]. (a-c) Recorded peak ground motion values (from Kik-Net, KNET and KKNPP database); (b-d) SEM3D simulations performed by introducing point-wise double couple source with different SVF: red circles and blue triangles refer to Brune $\left(u^{E X P}\right)$ and a Bouchon's $\left(u^{T N H}\right)$ functions respectively, with free-parameter $\tau_{R}=\tau_{R 1}=0.12 \mathrm{~s}$; green triangles refer to a Bouchon's ramp function with free-parameter $\tau_{R}=\tau_{R 2}=0.82 \mathrm{~s}$ instead.

both the recorded mean PGAs and PGVs $(+/-\sigma)$, although a slight overestimation may be noticed at larger source-to-site distance. This discrepancy might be due both to the location (the Kanto district is placed south-westward the Niigata prefecture) and to the magnitude (greater or equal to 5.0) to calibrate the GMPE parameters ([55]). However, Figures $8 \mathrm{~b}$ - $8 \mathrm{~d}$ suggest that the choice of a rise time $\tau_{R 1}$ (for either $u_{S}^{E X P}$ or $u_{S}^{T N H}$ ) is the most consistent with the selected GMPE [54], so it has been chosen as the suitable STF for the AS analyses.

\section{Effect of the topographical surface}

The final step of the numerical exercise presented in this paper consisted into adding the topographical surface (TOPO) to the previously calibrated flat model (FLAT). Figure 9 shows the 
computational mesh. The latter was routinely generated on parallel architecture, by exploiting

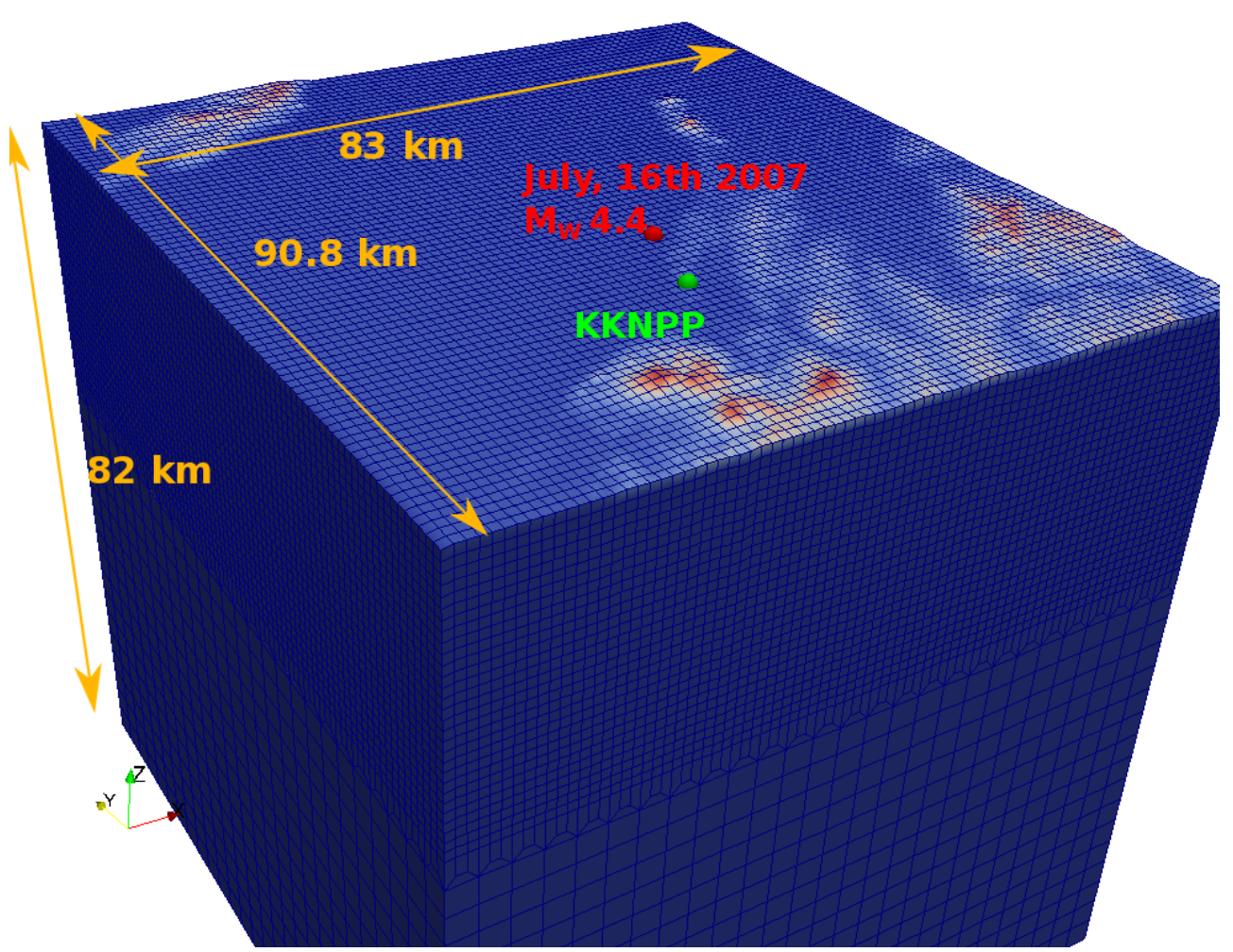

Figure 9: Sketch of the numerical model designed for the NCOEQ2007 scenario. The mesh has been The minimum element size (at surface, for a $V_{S}$ ) is $1000 \mathrm{~m}$, featured by 10 integration points.

Octree data structures [56]. A $90 \mathrm{~km} \times 83 \mathrm{~km} \times 82 \mathrm{~km}$ region in the surrounding of the KKNPP was meshed with 8-nodes tetrahedra, by extruding the local Digital Elevation Model (DEM), obtained from the SRTM database (http://dds.cr.usgs.gov/srtm/version2_1). The mesh was coarsened along depth (below $15 \mathrm{~km}$ of depth). 10 Gauss-Lobatto-Legendre (GLL) integration nodes were chosen to propagate a seismic wave-field up to $\approx 5 \mathrm{~Hz}$. The shear-wave velocity profile (Aochi2013 model) was implemented via a not honouring approach (Figure 4b). The Sea of Japan is not taken into account: a flat solid surface was considered instead. Figure 10 shows the comparison between the accelerograms obtained at the ground level at KKNPP site, for the FLAT (red line) and TOPO (blue line) model. The wave-forms were band-pass filtered between 0.1 and $5 \mathrm{~Hz}$. Early wave arrivals at higher frequencies are observed when the topographical surface is included in the model, although it does not seem to consistently affect the radiated wave-field. This aspect might be due to the fact that the Japan sea was disregarded. Finally, Figure 11 shows the synthetic velocigrams generated by SEM3D physics-based simulation at different locations nearby the Kashiwazaki-Kariwa Nuclear Power Plant. The synthetics wave-forms were band-pass filtered between 0.1 and $5 \mathrm{~Hz}$. The typical velocity pulses are visible in the near field (i.e. KKNPP, NIG018, NIG016), and high-frequency late arrivals may be observed in far field (NIG004 and NIGH12). 


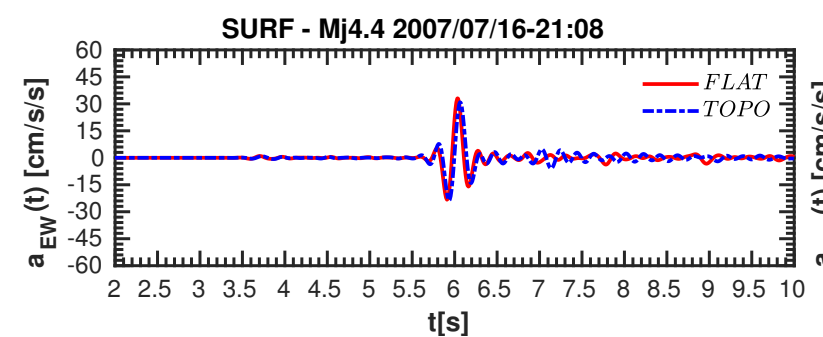

(a)

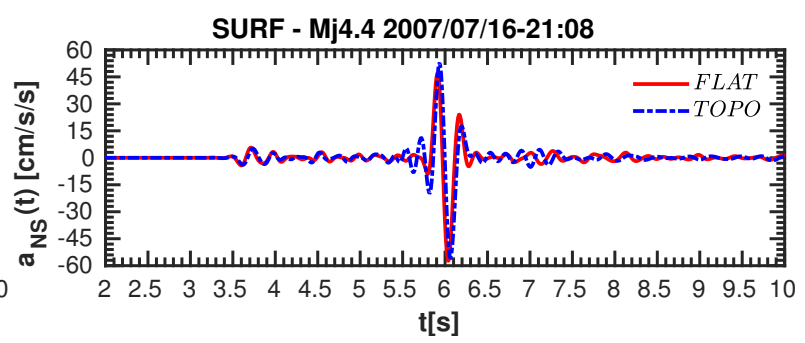

(b)

Figure 10: Numerical verification of SEM3D code: effect of the topographical surface. Synthetic wave-forms obtained at KKNPP (at surface) are portrayed: (a) EW component, (b) NS component.

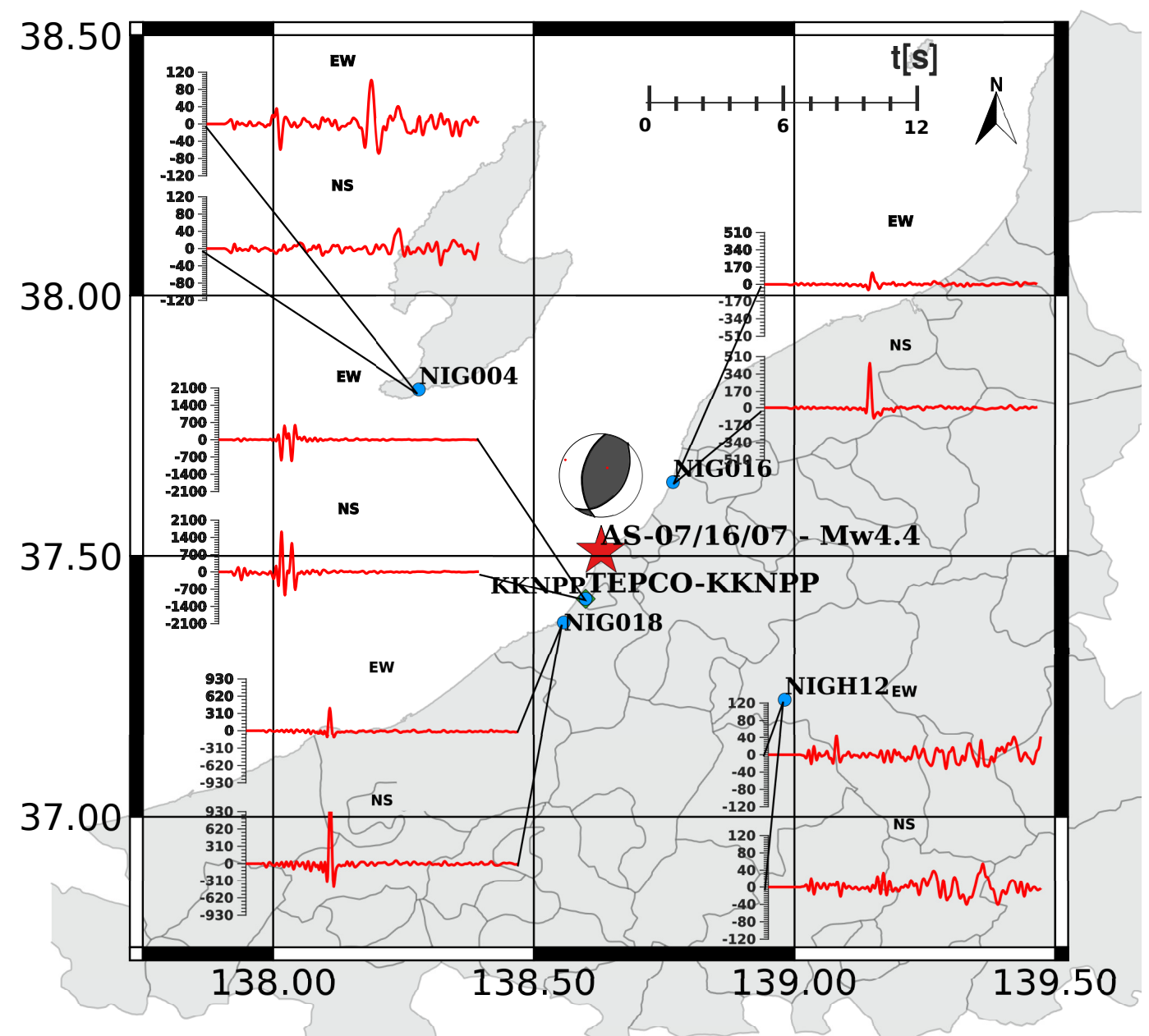

Figure 11: Simulations performed by SEM3D analysis of the NCOEQ2007 $\mathrm{M}_{j} 4.4$ aftershock of July 16, 21.08h. Synthetic wave-forms were obtained by considering the soil profile Aochi2013 (Figure 2). Velocigrams (expressed in $\mathrm{cm} / \mathrm{s}$ ) were amplified by a factor 1000 and locally aligned at the time-step corresponding to the $\% 1$ of the Arias intensity. 


\section{CONCLUSIONS AND PERSPECTIVES}

In this paper, the preliminary calibration of a 3D physics-based scenario of the Niigata-Ken Chüetsu-Oki earthquake is presented. The holistic approach adopted leads to focus on the coherent methodology to assess all its different tasks. The study highlights the inherent difficulty residing in each steps of the process, showing the necessity of an accurate uncertainty estimation along with each parameter setting. The focus of this work was mainly oriented to quantify (1) the effect of the regional stratified geology, (2) the model sensitiveness to the source parameters (even for a point-wise small aftershock) and (3) the implications of considering or neglecting the topographical surface. In this context, it is always useful to test each feature of the model against traditional approaches (e.g. the semi-analytical solutions, the Ground Motion Prediction Equations). Those tools provide a fast preliminary estimation of the model sensitiveness and therefore they help in understanding the crucial aspects of the scenario. To this respect, the way the parameter are tuned is pre-based on the experience gained from several earthquake modellings so to be coherent with the observations. However, site-specific conditions are extremely heterogeneous from case to case, thus requiring a huge effort in quantitatively solving the epistemic uncertainty. An effective probabilistic approach may be contemplated, starting from the most conservative choice of the parameter distribution, although one must bare in mind the onerous computational effort required. The 3D physics-based analyses presented in this work are preliminary, and a further detailing exercise is demanded so to assess the effect of (1) the complex geological structure (i.e. folded basin underneath KKNPP), (2) the non-linear mechanical behaviour of shallow sediments, (3) the effect of an heterogeneous crustal bedrock on the radiated wave-field, (4) the impact of the water presence on the S-wave component. Finally, the main-shock scenario will require the construction and calibration of an extended fault mechanism, either by described by kinematic approach either by simulating the dynamic rupture of the fault plane. All this improvements should be verified accordingly to the observations, especially highlighting the variations in the near field (i.e., $<10 \mathrm{~km}$ ). 


\section{ACKNOWLEDGEMENTS}

This work, within the SINAPS@ project, benefited from French state funding managed by the National Research Agency under program RNSR Future Investments bearing reference No. ANR-11-RSNR-0022-04. The research reported in this paper has been supported in part by the SEISM Paris Saclay Research Institute. Time histories and velocity profiles used in this study were collected from the KiK-net website: http://www.kik.bosai.go.jp/kik/ (last accessed November 2011). The authors are very grateful to the National Research Insti- tute for Earth Science and Disaster Prevention (NIED) for providing such high- quality earthquake recordings.

Time histories and velocity profiles used in this study were collected from the KiK-net website: http://www.kik.bosai.go.jp/kik/ (last accessed November 2011). The authors are very grateful to the National Research Institute for Earth Science and Disaster Prevention (NIED) for providing such high- quality earthquake recordings.

\section{REFERENCES}

[1] H. Aochi, A. Ducellier, F. Dupros, M. Delatre, T. Ulrich, F. de Martin, M. Yoshimi, "Finite difference simulations of seismic wave propagation for the $2007 \mathrm{Mw} 6.6$ Niigata-ken Chuetsu-Oki earthquake: Validity of models and reliable input ground motion in the near field", Pure and Applied Geophysics, 170((1-2)): 43-64, 2013, Springer Verlag (Germany).

[2] E. Yee, J. Stewart, K. Tokimatsu, "Nonlinear Site Response and Seismic Compression at Vertical Array Strongly Shaken by the Niigata-ken Chuetsu-Oki Earthquake", Technical report, Pacific Earthquake Engineering Research Center-College of Engineering University of California, Berkeley, 2011.

[3] O.V. Pavlenko, K. Irikura, "Nonlinear Soil Behavior at the Kashiwazaki-Kariwa Nuclear Power Plant During the Niigata Chuetsu-Oki Earthquake (July, 16, 2007)", Pure and Applied Geophysics, 169(10): 1777-1800, Jan. 2012, ISSN 0033-4553.

[4] R. Kayen, S.J. Brandenberg, B.D. Collins, S. Dickenson, S. Ashford, Y. Kawamata, Y. Tanaka, H. Koumoto, N. Abrahamson, L. Cluff, K. Tokimatsu, T. Kobeyasawa, N. Marubashi, S. Pujol, C. Steele, J.I. Sun, B. Tsai, P. Yanev, M. Yashinsky, K. Yousok, "Investigation of the M6.6 Niigata-Chuetsu Oki, Japan, Earthquake of July 16, 2007", Technical Report 1365, U.S. Department of the Interior and U.S. Geological Survey (USGS), 2007.

[5] R. Kayen, S.J. Brandenberg, B.D. Collins, S. Dickenson, S. Ashford, Y. Kawamata, Y. Tanaka, H. Koumoto, N. Abrahamson, L. Cluff, K. Tokimatsu, L. Johnson, "Geoengineering and Seismological Aspects of the Niigata-Ken Chuetsu-Oki Earthquake of 16 July 2007”, Earthquake Spectra, 25(4): 777-802, 2009.

[6] S. Aoi, H. Sekiguchi, N. Morikawa, T. Kunugi, "Source process of the 2007 Niigataken Chuetsu-Oki earthquake derived from near-fault strong motion data", Earth, Planets Space, 60(11): 1131-1135, 2014.

[7] A. Kato, S. Sakai, E. Kurashimo, T. Igarashi, T. Iidaka, N. Hirata, T. Iwasaki, T. Kanazawa, "Imaging heterogeneous velocity structures and complex aftershock distributions in the 
source region of the 2007 Niigataken Chuetsu-Oki Earthquake by a dense seismic observation", Earth, Planets Space, 60: 1111-1116, 2008.

[8] K. Hijikata, H. Nishimura, I.and Mizutani, R. Tokumitsu, M. Mashimo, S. Tanaka, "Ground motion characteristics of 2007 Niigata-ken Chuetsu-Oki earthquake", Journal of Structural and Construction Engineering, 75(653): 1279-1288, 7 2010, ISSN 13404202.

[9] K. Tsuda, T. Hayakawa, T. Uetake, K. Hikima, R. Tokimitsu, H. Nagumo, Y. Shiba, "Modeling 3D Velocity Structure in the Fault Region of the 2007 Niigataken Chuetu-Oki Earthquake with Folding Structure", in $4^{\text {th }}$ IASPEI/IAEE International Symposium-Effects of Surface Geology on Seismic Motion, pages 1-11, 2011.

[10] R. Tokumitsu, M. Kikuchi, I. Nishimura, Y. Shiba, S. Tanaka, "Analysis of the strong motion records obtained from the 2007 Niigataken Chuetsu-Oki earthquake and determination of the design basis ground motions at the Kashiwazaki Kariwa Nuclear Power Plant. Part 1. Outline of the strong motion records and estimation of factors in large amplification", Technical report, 2009.

[11] Y. Yukutake, T. Takeda, K. Obara, "Well-resolved hypocenter distribution using the double-difference relocation method in the region of the 2007 Chuetsu-Oki Earthquake", Earth, Planets and Space, 60(11): 1131-1135, Nov. 2008.

[12] A. Cirella, A. Piatanesi, E. Tinti, M. Cocco, "Rupture process of the 2007 Niigataken Chuetsu-Oki earthquake by non-linear joint inversion of strong motion and GPS data", Geophysical Research Letters, 35(16): 1-5, 2008.

[13] H. Miyake, K. Koketsu, K. Hikima, M. Shinohara, T. Kanazawa, "Source Fault of the 2007 Chuetsu-Oki, Japan, Earthquake", Bulletin of the Seismological Society of America, 100(1): 384-391, Jan. 2010.

[14] Y. Shiba, "Source process and broadband strong motions during the Niigata-ken ChuetsuOki earthquake in 2007", Denryoku Chuo Kenkyusho Hokoku, (N08007): 1-4, 2008, Japanese with English Abstract.

[15] H. Aochi, T. Ulrich, A. Ducellier, F. Dupros, D. Michea, "Finite difference simulations of seismic wave propagation for understanding earthquake physics and predicting ground motions: Advances and challenges", in $24^{\text {th }}$ IUPAP Conference on Computational Physics (IUPAP-CPP 2012), Volume 454 of Journal of Physics, pages 43-64. IOP, 2013.

[16] Y. Shiba, K. Hikima, T. Uetake, H. Mizutani, H. Tsuda, T. Hayakawa, S. Tanaka, "Source model of the 2007 Chuetsu-Oki earthquake based on precise aftershock distribution and 3D velocity structure", in Japan Geoscience Union meeting, 2011.

[17] T. Uetake, R. Tokumitsu, I. Nishimura, K. Hijikata, "Effects of fold structure in the kashiwazaki-kariwa nuclear power station on the ground motion characteristics of Niigataken Chuetsu-Oki Earthquake: Modeling of sub-surface structure and wave propagation study using a finite difference method", Journal of Structural and Construction Engineering, 76(660): 311-318, 2011, ISSN 1340-4202. 
[18] A. Ducellier, H. Aochi, "Numerical simulation of the Mw 6.6 Niigata, Japan, earthqhake: Reliable input ground motion for engineering purpose", in $14^{\text {th }}$ European Conference on Earthquake Engineering, 2010.

[19] K. Hikima, K. Koketsu, "Source process of the 2007 Chuetsu-Oki earthquake inferred from far field waveforms and strong motions", Fall Meeting 2007, pages 1-85. Seismological Society of Japan, 2007.

[20] H. Aochi, M. Yoshimi, "Seismological asperities from the point of view of dynamic rupture modeling: the 2007 Mw6. 6 Chuetsu-Oki, Japan, earthquake", Journal of Seismology, 20(4): 1089-1105, 2016.

[21] Y. Hisada, “An efficient method for computing Green's Functions for layered half-space with sources and receivers at close depths", Bulletin of the Seismological Society of America, 84(5): 1456-1472, October 1994.

[22] Y. Hisada, "An efficient method for computing Green's functions for a layered half-space with sources and receivers at close depths (part 2)", Bulletin of the Seismological Society of America, 85(4): 1080-1093, August 1995.

[23] E. Faccioli, F. Maggio, R. Paolucci, A. Quarteroni, “2D and 3D elastic wave propagation by a pseudo-spectral domain decomposition method", Journal of Seismology, 1(3): 237$251,1997$.

[24] D. Komatitsch, J.P. Vilotte, "The Spectral Element Method: An Efficient Tool to Simulate the Seismic Response of 2D and 3D Geological Structures", Bulletin of the Seismological Society of America, 88(2): 368-392, 1998.

[25] D.M. Boore, "Simulation of Ground Motion Using the Stochastic Method", Pure and Applied Geophysics, 160(3): 635-676, Mar. 2003.

[26] K. Kamae, K. Irikura, A. Pitarka, "A Technique for Simulating Strong Ground Motion Using Hybrid Green's Functions”, Bulletin of the Seismological Society of America, 88 (2): 357-367, 1998.

[27] S. Hartzell, P. Liu, C. Mendoza, "The 1994 Northridge, California, earthquake: Investigation of rupture velocity, risetime, and high-frequency radiation", Journal of Geophysical Research, 101(B9): 20091-20108, 1996.

[28] P. Somerville, K. Irikura, N. Abrahamson, S. Sawada, T. Kagawa, A. Tatsumi, "Characterizing earthquake slip models for the prediction of strong ground motion", Seismological Research Letters, 70: 59-80, 1999.

[29] D. Göddeke, D. Komatitsch, M. Möller, Finite and Spectral Element Methods on Unstructured Grids for Flow and Wave Propagation Methods, Chapter 9, pages 183-206, Springer, 2014.

[30] R. Paolucci, I. Mazzieri, C. Smerzini, M. Stupazzini, "Physics -Based Earthquake Ground Shaking Scenarios in Large Urban Areas", in A. Ansal (Editor), Perspectives on European Earthquake Engineering and Seismology, Volume 1 of Geotechnical, Geological and Earthquake Engineering - Vol.34, pages 331-359. Springer, 2014. 
[31] E. Maufroy, E. Chaljub, F. Hollender, J. Kristek, P. Moczo, P. Klin, E. Priolo, A. Iwaki, T. Iwata, V. Etienne, F. De Martin, N.P. Theodoulidis, M. Manakou, C. Guyonnet-Benaize, K. Pitilakis, P.Y. Bard, "Earthquake Ground Motion in the Mygdonian Basin, Greece: The E2VP Verification and Validation of 3D Numerical Simulation up to $4 \mathrm{~Hz}$ ", Bulletin of the Seismological Society of America, 105(3): 1398-1418, June 2015.

[32] F. De Martin, "Verification of a Spectral-Element Method Code for the Southern California Earthquake Center LOH.3 Viscoelastic Case", Bulletin of the Seismological Society of America, 101(6): 2855-2865, December 2011.

[33] M. Shinohara, T. Kanazawa, T. Yamada, K. Nakahigashi, S. Sakai, R. Hino, Y. Murai, A. Yamazaki, K. Obana, Y. Ito, et al., "Precise aftershock distribution of the 2007 ChuetsuOki Earthquake obtained by using an ocean bottom seismometer network", Earth, planets and space, 60(11): 1121-1126, 2008.

[34] A. Kato, E. Kurashimo, T. Igarashi, S. Sakai, T. Iidaka, M. Shinohara, T. Kanazawa, T. Yamada, N. Hirata, T. Iwasaki, "Reactivation of ancient rift systems triggers devastating intraplate earthquakes", Geophysical Research Letters, 36(5), 32009.

[35] H. Sekiguchi, M. Yoshimi, H. Horikawa, K. Yoshida, H. Suzuki, H. Matsuyama, M. Morino, F. Takizawa, L. Ying, "3D subsurface structure model of the Niigata sedimentary basin”, Ann. Rep. Active Fault Paleoearthq. Res., 9: 175-259, 2009.

[36] K. Hikima, K. Koketsu, "Rupture processes of the 2004 Chuetsu (mid-Niigata prefecture) earthquake, Japan: A series of events in a complex fault system", Geophysical Research Letters, 32(18), Sept. 2005.

[37] K. Obara, K. Kasahara, S. Hori, Y. Okada, "A densely distributed high-sensitivity seismograph network in Japan: Hi-net by National Research Institute for Earth Science and Disaster Prevention”, Review of Scientific Instruments, 76, 2005, ISSN 021301.

[38] Y. Okada, K. Kasahara, K. Hori, S. Obara, H. Sekiguchi, S. Fujiwara, A. Yamamoto, "Recent progress of seismic observation networks in Japan -Hi-net, F-net, K-NET and KiK-net”, Earth, Planets and Space, 56: xv-xxviii, 2004.

[39] R.J. Geller, "Scaling relations for earthquake source parameters and magnitudes", Bulletin of the Seismological Society of America, 66(5): 1501-1523, 1976.

[40] K. Irikura, "Semi-Empirical Estimation of Strong Ground Motions During", Bulletin of the Disaster Prevention Research Institute, 33(2): 63-104, 1983.

[41] T. Yokoi, K. Irikura, "Empirical Green's function technique based on the scaling law of source spectra", Zisin (Journal of the Seismological Society of Japan. 2nd ser.), 2(44): 109-122, 1991.

[42] H. Miyake, T. Iwata, K. Irikura, "Source characterization for broadband ground-motion simulation. Kinematic heterogeneous source model and strong motion generation area", Bulletin of the Seismological Society of America, 93(6): 2531-2545, 2003.

[43] A. Bizzarri, "On the point-source approximation of earthquake dynamics", Annals of Geophysics, 57(3), 2014. 
[44] R. Madariaga, Seismic Source Theory, Chapter 4.02, Elsevier BV, Paris, France, 2007.

[45] M. Bouchon, “A simple method to calculate Green's functions for elastic layered media", Bulletin of the Seismological Society of America, 71(4): 959-971, 1981.

[46] J.N. Brune, "Tectonic stress and the spectra of seismic shear waves from earthquakes", Journal of Geophysical Research, 75(26): 4997-5009, 1970.

[47] Z. Duputel, V.C. Tsai, L. Rivera, H. Kanamori, "Using centroid time-delays to characterize source durations and identify earthquakes with unique characteristics", Earth and Planetary Science Letters, 374: 92-100, 2013.

[48] K. Aki, P. Richards, Quantitative Seismology-Theory and Methods, Volume I-II of Books in Geology, W.H Freeman and Company, San Francisco (USA), 1980.

[49] F. De Martin, H. Aochi, E. Foerster, "Testing the Double-Couple Point Source Model in GEFDYN", Technical report, BRGM, 2007.

[50] D. Dreger, G. Hurtado, A.K. Chopra, S. Larsen, "Near-Fault Seismic Ground Motions", Technical Report 59A0435, California Department of Transportation, 2007.

[51] Z. Duputel, L. Rivera, H. Kanamori, G. Hayes, "W phase source inversion for moderate to large earthquakes (1990?2010)", Geophysical Journal International, 189(2): 1125, 2012.

[52] H. Kanamori, D.L. Anderson, "Theoretical basis of some empirical relations in seismology”, Bulletin of the Seismological Society of America, 65(5): 1073-1095, 1975.

[53] K. Aki, "Scaling law of seismic spectrum", Journal of Geophysical Research, 72(4): 1217-1231, 21967.

[54] S. Fukushima, "Seismic hazard analysis based on the joint probability density function of PGA and PGV", in Transactions, SMiRT 19, Volume M03, 2007.

[55] F. Cotton, G. Pousse, F. Bonilla, F. Scherbaum, "On the discrepancy of recent European ground-motion observations and predictions from empirical models: Analysis of KiK-net accelerometric data and point-sources stochastic simulations", Bulletin of the Seismological Society of America, 98(5): 2244-2261, 2008.

[56] J.J. Camata, A.L.G.A. Coutinho, "Parallel implementation and performance analysis of a linear octree finite element mesh generation scheme", Concurrency and Computation: Practice and Experience, 25(6): 826-842, 2013. 